\title{
Constant seed size and mandible growth - a fundamental problem for granivorous ground beetle larvae (Coleoptera: Carabidae)
}

\author{
Wilfried Paarmann, Nicolas Faust, Erik Arndt, Ingrid Lüchtrath \& Wolfgang Rohe
}

Paarmann, W., Faust, N., Arndt, E., Lüchtrath, I. \& Rohe, W. 2006: Constant seed size and mandible growth - a fundamental problem for granivorous ground beetle larvae (Coleoptera: Carabidae). — Entomol. Fennica 17: 334-339.

Feeding on small tree seeds at fruit falls is a specific adaptation of harpaline ground beetles and their larvae in tropical rain forests. Using mandibles as tools, they have to perforate the seed shell to reach the nutritious interior. The isometric growth of larval mandibles, known from predatory species, would result in a changing ratio between seed and mandible size during the course of development. The stable size of host tree seeds should select an optimum mandible size, similar for the three larval instars in spermophageous species. We found an increasing tendency to maintain the length of the apical mandible part (apex) in seed feeding species. The size increase is higher in the species from Australia, Africa and South East Asia than in the New World species of the genus Notiobia. Feeding experiments have revealed that larvae of species with a stronger increase in apex growth are also able to develop as predators of Drosophila larvae. Our results furthermore point to an influence of beetle size and shell hardness of the host tree seeds on the apex size and its growth rate.

W. Paarmann, N. Faust, I. Lüchtrath and W. Rohe, HAWK, Fakultät Ressourcenmanagement, Büsgenweg 1 A, D-37077 Göttingen, Germany

E. Arndt, Anhalt University, Department 1, Strenzfelder Allee 28, D-06406 Bernburg, Germany

Received 15 January 2006, accepted 30 June 2006

\section{Introduction}

Ground beetle species feeding on small tree seeds are so far only reported from tropical lowland rain forests (Borcherding et al. 2000, Paarmann et al. 2001, 2002, 2003, Arndt \& Kirmse 2002). The ancestors of harpaline ground beetles were carnivorous species (Beutel 1997, Zetto Brandmayr et al. 1998). The change from an originally carnivorous life habit to spermatophagy may be the result of selective forces caused by a general shortage of prey on the soil surface (Erwin 1979), while ample seed supply is available, although this is restricted in space and time. Many tree species in the Amazonian lowland forests produce such abundant seed resource: Ficus spp. (Moraceae), Bellucia spp., Loreya spp., Miconia spp. (Melastomatacea), Coussapoa asperifolia (Cecropiaceae), Goupia glabra (Celestracea) and Vismia guianensis (Clusiaceae) (Arndt \& Kirmse 2002, Paarmann et al. 2000, 2002, 2003). In the South-East Asian (Borcherding et al. 2000), the 


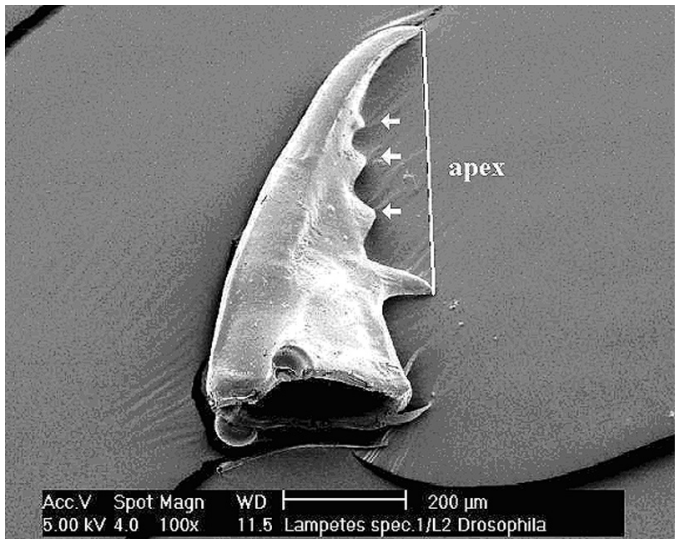

Fig. 1. Notiobia mandible. Arrows indicate additional terebral teeth typical for larval mandibles of most of the seed-feeding ground beetle species in tropical rain forests. Apex size is defined as being the distance between the tip of the mandible and the tip of the retinaculum (see Tables 1-2).

Australian (Kowalski 2004), and African (Paarmann et al. unpubl. data) rain forests, Ficus spp. play a similar role. Kowalski (2004) added Dendrocnide photinophylla (Urticaceae) to the group of host plants in the Australian rain forest. The biggest seeds of these host plants are that of Goupia glabra with $2.3 \mathrm{~mm}$ length and $1.1 \mathrm{~mm}$ width (Arndt \& Kirmse 2002).

On their way to adapt to a seed-feeding habit, the beetle species with larvae specialized to one type or size of seed had to solve a fundamental problem: the seeds remain the same size while the seed-shell perforating tools (mandibles) of the larvae increase during the development from the first to the third instar. The functional part of a nut-cracker, optimal for opening a nut of certain size and shape, should be kept at the same size during the general enlargement of the larva. Arndt \& Kirmse (2002) were the first to show that there is a tendency among the seed-feeding larvae to reduce the enlargement of the apex (distance between the tip of the mandible and the tip of the retinaculum; Fig. 1) among different larval stages. Consequently, the percentage of apex growth between the first and the third larval instars can be used as a simple measure for characterising the degree of larval specialization, caused by the force to keep their nut-cracker at an optimal size during body enlargement.

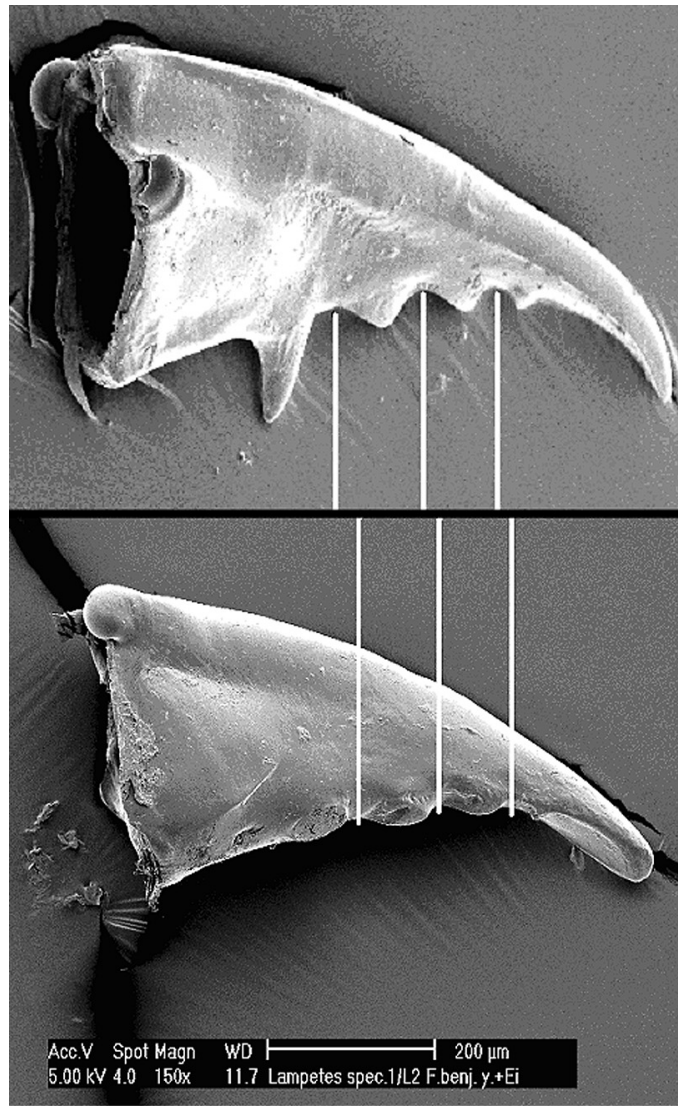

Fig. 2. Abrasions of the larval mandible, caused by hard seed shells: second-instar mandibles of Lampetes sp. 1, fed with Drosophila larvae (up) and fed with Ficus benjamina seeds (down).

In this paper, we provide additional support for this hypothesis, using new material. While Kirmse and Arndt (2002) used larvae from field catches (which often show abrasions at the apex site, Fig. 2) and compared the tropical seed feeders with predatory species from temperate regions, we used mandibles of larvae from feeding experiments with Drosophila larvae or wild poppy (Papaver rhoeas) seeds, which do not cause abrasions. Furthermore, we compared data from seed-feeding species with data from a predatory species, commonly appearing on fig fruit falls in the Australian rainforest. Arndt and Kirmse (2002) measured only species from a South American rain forest; we also included species from Australian, African and South East Asian rain forests. 


\section{Material and methods}

We measured the apex of larval mandibles of 11 ground beetle species originating from fruit fall sites in different tropical lowland rainforests. The parental stock of seven Notiobia species was collected during field studies in the Reverva Florestal Adolpho Duke near Manaus (Amazonia, Brazil); for details, see Paarmann et al. (2001, 2002, 2003). The parental stock of Lampetes sp. 1 was collected during field studies in Brunei (Borneo); for details, see Borcherding et al. (2000). The Coleolissus papua and Trichotichnus storeyi breeding stock was collected in the Natural Reserves 'Lake Barin' and 'Lake Eacham' in the Tablelands of Queensland (Australia) during field studies in 2000 and 2001. Platymetopus sp. was collected during February 2004 in the Kakamega Forest, Western Kenya, Africa.

The mandibles used for the measurements were collected during feeding experiments; these are described in detail by Paarmann (2002). To estimate the growth of the apex, we measured the distance between the tip of the mandible and the tip of the retinaculum (Fig. 1) with a microscope under 10x magnification that allowed a precision of $5 \mu \mathrm{m}$. Only mandibles from larvae fed with Drosophila larvae or wild poppy were used to avoid an influence of abrasions. For the descriptive statistics and the statistical analysis ( $F$-test, Student's $t$-test) we used Microsoft Excel and WinSTAT. SEM (scanning electron microscope) photos were taken with the help of the Max Planck Institute, Göttingen. The assessment criteria of food quality for the development of ground beetle species was described in detail in Paarmann (2002). We used a score system between 0 (larva died without feeding) and 10 points (the hatched beetle survived for at least two months). To describe food quality, we used the average score points, together with the percentage of larvae that reached 10 points. We also counted the number of seeds consumed during each larval instar.

\section{Results}

We found differences in the size enlargement of the apical part of the mandibles (apex) between

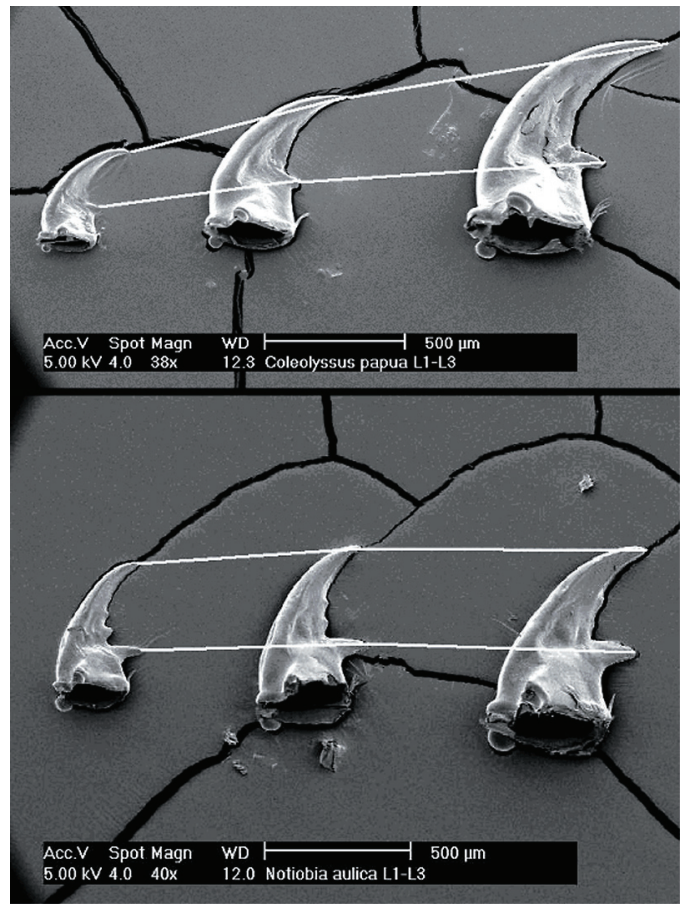

Fig. 3. Apex growth in the predatory species Coleolissus papua from the first to the second and the third instars (up) and in the South American seed feeder Notiobia aulica (down). White lines connect tips of mandibles and tips of retinaculi.

the studied species (subfamily Harpalinae). Differences in growth were connected to the feeding habits of different species. The predatory species C. papua doubled its apex length from the first to the third instar, while the apex length was only $17.1 \%$ longer in the third $v s$. in the first larval instar in the seed-feeding $N$. aulica (see also Table 1). Fig. 3 illustrates these two different types of mandible apex growth. The data of all measurements are pooled in Table 1.

In all, $66 \%( \pm 5.1 \% \mathrm{SD})$ of all seeds eaten during development were consumed during the third larval instar in all the seed-feeding species [pooled data from all ten studied spermatophageous species; $n=90$; ten individuals of each species except $N$. aulica $(n=7)$ and $N$. maxima $(n$ $=3)]$. Therefore, we assumed that the apex should reach its optimal size at this stage; hence this measure was used as the base of comparisons (Table 2).

If offered Drosophila larvae as prey, the nonAmerican species reached high average food suit- 
Table 1. Apex size $(\mu \mathrm{m})$ of the three larval instars (with SD and $n$, i.e., the number of measured mandibles at each instar) in several examined carabid species of the subfamily Harpalinae. Coloelissus papua is a predatory species, all the other species are spermophageous. Continent $=$ continent of origin $(\mathrm{Au}=$ Australia, $\mathrm{Af}=$ Africa, $\mathrm{SEAs}=$ South - East Asia, SAm $=$ South America $)$.

\begin{tabular}{|c|c|c|c|c|c|c|c|c|c|c|}
\hline \multirow[t]{2}{*}{ Species } & \multicolumn{3}{|c|}{ 1. instar } & \multicolumn{3}{|c|}{ 2. instar } & \multicolumn{3}{|c|}{ 3. instar } & \multirow[t]{2}{*}{ Continent } \\
\hline & Size & SD & $n$ & Size & SD & $n$ & Size & SD & $n$ & \\
\hline Coloelissus papua Darlington & 260.0 & 5.3 & 12 & 366.0 & 15.8 & 15 & 531.8 & 30.4 & 17 & $\mathrm{Au}$ \\
\hline Trichotichnus storeyi Baehr & 302.5 & 14.9 & 12 & 375.8 & 9.0 & 12 & 490.0 & 11.3 & 12 & $\mathrm{Au}$ \\
\hline Platymetopus sp. & 418.5 & 7.5 & 20 & 507.7 & 9.2 & 20 & 600.5 & 13.1 & 20 & Af \\
\hline Lampetes sp. 1 & 406.7 & 6.6 & 21 & 453.5 & 10.4 & 20 & 531.5 & 18.1 & 20 & SEAs \\
\hline Notiobia flavicinctus Erichson & 411.3 & 11.0 & 28 & 475.7 & 17.0 & 30 & 526.1 & 17.2 & 33 & SAm \\
\hline \multicolumn{11}{|c|}{ Notiobia pseudolimbipennis } \\
\hline Arndt & 582.5 & 17.7 & 12 & 645.7 & 19.1 & 14 & 726.2 & 32.3 & 13 & SAm \\
\hline Notiobia umbrifera Bates & 328.1 & 16.0 & 16 & 362.5 & 13.4 & 16 & 401.1 & 15.2 & 19 & SAm \\
\hline Notiobia nebrioides Perty & 446.5 & 10.0 & 17 & 467.9 & 21.2 & 14 & 530.7 & 17.3 & 14 & SAm \\
\hline Notiobia aulica Dejean & 335.0 & 14.6 & 16 & 355.6 & 13.8 & 18 & 392.3 & 21.3 & 13 & SAm \\
\hline Notiobia glabrata Arndt & 395.3 & 14.6 & 17 & 411.3 & 19.6 & 16 & 458.3 & 11.5 & 18 & SAm \\
\hline Notiobia maxima Arndt & 417.5 & 32.0 & 4 & 437.5 & 26.3 & 4 & 440.0 & 8.2 & 4 & SAm \\
\hline
\end{tabular}

ability scores, similar to the pure predatory species $C$. papua (Table 2). The average scores of the Notiobia species that fed on fruit flies were lower, and only two of them survived to the adulthood.

In two beetle pairs of different body size, each adapted to the same seed type ( $N$. umbrifera/N. aulica to Miconia, and N. glabrata/N. maxima to Bellucia), we found similar apex sizes in the third larval instar of the different species (Table 2). A third pair, specialized on fig seeds ( $N$. flavi-
cinctus/N. pseudolimbipennis), significantly differed in their apex size (Table 2). There was no overlap between the apex sizes of these two species. The medium apex size of the third larval instar of the smaller species, $N$. flavicinctus, was distinctly lower than the apex size of the first larval instar of the bigger species, N. pseudolimbipennis (Student's $t$-test, $\mathrm{p}<0.0001$ ). The seeds of their host plants were all in the same size range (length $0.8-1.2 \mathrm{~mm}$, width $0.7-0.8 \mathrm{~mm}$;

Table 2. Apex growth from the first to the third larval instar (\% enlargement). The columns are from left to right: Species (note that C. papua is a predatory species); \% apex g. = \% apex growth; Score p. = score points; $\% 10$ p. $=\%$ larvae that reached 10 points (see text); Elytra = length of elytra in $\mathrm{mm}$; SD = standard error for the length of elytra; $n=$ number of specimens measured for the length of elytra; Apex size = apex size in the third instar in $\mu \mathrm{m}$ (for three beetle species pairs). Italics - specialized on fig seeds, underlined - specialized on Miconia seeds, bold - specialized on seeds of Bellucia and Loreya.

\begin{tabular}{lrrrrrrr}
\hline Species & \% apex g. & Score p. & $\% 10$ p. & Elytra & SD & $n$ & Apex size \\
\hline Coloelissus papua & 104.6 & 8.4 & 35 & 8.0 & 0.2 & 6 & - \\
Trichotichnus storeyi & 52.0 & 8.1 & 56 & 5.5 & 0.2 & 19 & - \\
Platymetopus sp. & 43.5 & 8.8 & 40 & - & - & - & - \\
Lampetes sp. 1 & 30.7 & 8.2 & 37 & 6.2 & 0.1 & 21 & - \\
Notiobia flavicinctus & 27.7 & 5.4 & 0 & 6.0 & 0.3 & 33 & 526.3 \\
Notiobia pseudolimbipennis & 24.7 & 5.5 & 0 & 8.2 & 0.3 & 26 & 726.2 \\
Notiobia umbrifera & 22.2 & 2.4 & 0 & 5.4 & 0.3 & 12 & $\underline{401.1}$ \\
Notiobia nebrioides & 18.9 & 6.0 & 0 & 8.2 & 0.5 & 21 & - \\
Notiobia aulica & 17.1 & 5.9 & 23 & 6.8 & 0.5 & 22 & $\underline{392.3}$ \\
Notiobia glabrata & 16.0 & 7.5 & 48 & 7.2 & 0.3 & 20 & $\mathbf{4 5 8 . 3}$ \\
Notiobia maxima & 5.4 & - & - & 9.0 & 0.3 & 21 & $\mathbf{4 4 0 . 0}$ \\
\hline
\end{tabular}




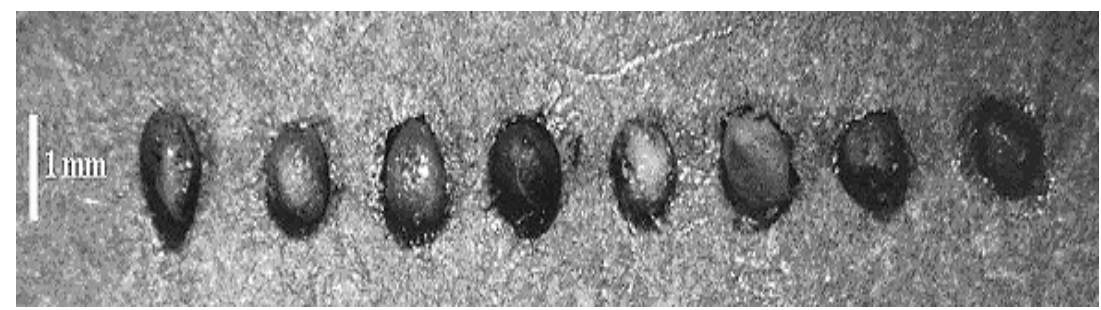

Fig. 4. Seeds (botanically defined as nuts) of fig species from the Amazonian rain forest near Manaus (Brazil). From left to right: Ficus guianensis, F. subapiculata, F. donellsmithii, F. hebetifolia, F. guianensis-complex, F. albert-smithii, F. mathewsii and $F$. greiffiana.

Fig. 4). During the third larval instar, larvae of the bigger species $N$. pseudolimbipennis opened on average 233.9 seeds $( \pm 51.2 \mathrm{SD} ; n=32), 121.1 \%$ more of Ficus seeds (pooled data for F. donellsmithii, F. guianensis and F. subapiculata) than the smaller species $N$. flavicinctus [mean 105.1 seeds $( \pm 19.1 \mathrm{SD} ; n=31)]$.

\section{Discussion}

A lower degree of apex growth was found in larvae of all the studied spermophageous ground beetle species, compared to the predatory ones [Table 2; see Arndt \& Kirmse (2002) for further data of carnivorous and omnivorous species]. If the reduction in apex growth correlates with the degree of adaptation to seed feeding from originally predatory species, this adaptation is more advanced in the South American species of the genus Notiobia than in the studied species from the other continents. A possible explanation of this phenomenon could be a larger seed and a lower prey resource at fruit falls in the Amazonian lowlands, compared to the situation in similar forests on other continents. This corresponds also with the percentage of seed-feeding individuals in the carabid assemblages: $92-98 \%$ in Brazil vs. 39\% in South-East Asia and 24\% in Australia (Borcherding et al. 2000, Kowalski 2004, Paarmann et al. 2001, 2002).

While the predatory species C. papua and the seed-feeding species from Africa, Australia and Borneo reach high average scores when fed with fruit fly larvae (Table 2), the Notiobia species do not show a clear correlation between apex growth and the ability to develop feeding only on Dro- sophila larvae. The lowest apex growth was found in N. maxima, the biggest species among the studied seed feeders. It seems plausible to assume that the biggest species should show the strongest reduction in apex growth, compared to the smaller species. Notiobia maxima is specialized to Bellucia and Loreya seeds (Paarmann et al. 2002). The smaller species $N$. glabrata is also very abundant at fruit falls of these tree species. Its larvae show a very similar apex size in the third larval instar (Table 2; due to the low sample size of $N$. maxima, no statistics were performed). To reach this size, the smaller species needs an apex growth of $16 \%$, compared to $5.4 \%$ in the bigger one. Similar conditions were found in the species pair $N$. aulica and N. umbrifera (Table 2, underlined numbers). Both of these species are specialized on Miconia seeds (Paarmann et al. 2002); they also have very similar apex sizes in the third instar (Student's $t$-test, $p=0.2$ ) and a stronger apex growth in the smaller species. The significant differences of about $50 \mu \mathrm{m}$ between the two species pairs ( $t$-test: for $N$. maxima $: N$. aulica and $N$. umbrifera, $p<0.001$ and for $N$. glabrata: $N$. aulica and $N$. umbrifera, $p<0.001$ ) may reflect the niche separation among the different Melastomatacea seed feeding specialists (Miconia and Bellucia/Loreya, respectively), found earlier by Paarmann et al. (2002) in the field. The two species, N. pseudolimbipennis and $N$. flavicinctus, specialized on fig seeds (Paarmann et al. 2001, Paarmann 2003) also differ in their body size (Table 2). In contrast to the species pairs adapted to Miconia or Bellucia, the apex size of the fig-seed feeders differed significantly (Table 2, numbers in Italics). This result could be interpreted as a clear niche separation - except 
that the seeds of the different fig species in their habitat are all in the same size range (Fig. 4), and both species reproduce at fruit falls of the same Ficus species (Paarmann et al. 2001). Feeding experiments (Paarmann 2002) showed that seeds of $F$. guianensis and $F$. donell-smithii are of similar high value to both beetle species. Ficus subapiculata appears to be a better host species for $N$. flavicinctus than for $N$. pseudolimbipennis, while $F$. hebetifolia represents the opposite. These differences may be caused by differences in shell hardness. The necessity for the bigger species to open a comparable high number of fig seeds (121.1\% more than $N$. flavicinctus) could lead to much stronger abrasions, followed by a loss of functionality (compare Fig. 2). The higher score values $N$. pseudolimpipennis reached, if fed with the seeds of $F$. hebetifolia, may be the result of a higher power in the bigger first larval instar compared to the small first instar larvae of $N$. flavicinctus.

Acknowledgements. B. Bleher, N. Farwig (JohannesGutenberg-Universität Mainz) and J. Holstein (Staatliches Museum für Naturkunde, Stuttgart) collected living ground beetle specimens in Kenya and organized their transport to Germany. The photos were taken under the advice and with the equipment of M. Stuke and K. Müller (Max-Planck-Institut für Biophysikalische Chemie, Göttingen).

\section{References}

Arndt, E. \& Kirmse, S. 2002: Adaptation to seed-feeding in ground beetles (Coleoptera: Carabidae: Harpalini) of South Venezuela. - Studies on Neotropical Fauna and Environment 31: 205-216.

Beutel, R. 1997: Über Phylogenese und Evolution der Coleoptera (Insecta), insbesondere der Adephaga. -
Abhandlungen der Naturwissenschaftlichen Vereinigung Hamburg (NF) 31. 164 pp.

Borcherding, R., Paarmann, W., Nyawa S. B. \& Bolte, H. 2000: How to be a fig beetle? Observations of ground beetles (Col., Carabidae) associated with fruit falls in a rain forest of Borneo. - Ecotropica 6: 169-180.

Erwin, T. L. 1979: Thoughts on the evolutionary history of ground beetles: hypotheses generated from comparative faunal analyses of lowland forest sites in temperate and tropical regions. - In: Erwin, T. L., Ball, G. E., Whitehead, D. R. \& Halpern, A. L. (eds.), Carabid beetles: their evolution, natural history and classification: 539-587. Dr. W. Junk, The Hague. 635 pp.

Kowalski, S. 2004: Potentielle Wirtsbäume des samenfressenden Laufkäfers Trichotichnus storeyi (Col., Carabidae) im australischen Regenwald. - Diploma thesis, Fachhochschule Hildesheim, Holzminden, Göttingen. $70 \mathrm{pp}$.

Paarmann, W., Adis, J., Stork, N. E., Gutzmann, B., Stumpe, P., Staritz, B., Bolte, H., Küppers, S., Holzkamp, K.; Niers, C. \& da Fonseca, C. R. V. 2001: The structure of ground beetle assembladges (Coleoptera: Carabidae) at fig fruit falls (Moraceae) in a terra firme rain forest near Manaus (Brazil). — Journal of Tropical Ecology 17: 549-561.

Paarmann, W., Gutzmann, B., Stumpe, P., Bolte, H., Küppers. S., Adis. J., Stork, N. E. \& da Fonseca, C. R. V. 2002: The structure of ground beetle assemblages (Coleoptera: Carabidae) at fruit falls of Melastomataceae trees in a Brazilian terra firme rain forest. Biotropica 34: 368-375.

Paarmann, W. 2002: Determination of food quality for successful development of seed-feeding ground beetles (Col., Carabidae) from tropical lowland rain forests. — In: Szyszko, J. et al. (eds.): How to protect or What we know about carabid beetles: 45-57. Agricultural University Press, Warszawa. 378 pp.

Paarmann, W., Adis, J., Stork, N. E., Stumpe, P., Gutzmann, B. \& Holzkamp. K. 2003: Finding the host tree species of Notiobia nebrioides Perty (Coleoptera, Carabidae), a member of the seed-feeding guild at fruit falls in Amazonian non-inundated lowland rainforests. - Journal of Natural History 37: 839-844.

Zetto Brandmayr, T., Giglio, A., Marano, I. \& Brandmayr, P. 1998: Morphofunctional and ecological features in carabid (Coleoptera) larvae. - Atti Museo Regionale di Scienze Naturali, Torino: 449-490. 